Giampiero Giovacchini*, Luca Giovanella, Andreas Haldemann, Uwe Staub, Frank G. Füchsel and Peter Koch

\title{
Potentiometric measurement of urinary iodine concentration in patients with thyroid diseases with and without previous exposure to non- radioactive iodine
}

DOI 10.1515/cclm-2015-0117

Received February 3, 2015; accepted February 20, 2015; previously published online March 18, 2015

\section{Abstract}

Background: Extensive application of measurement of urinary iodine concentration (UIC) in several benign and malignant thyroid diseases could profit by the availability of rapid and inexpensive measuring techniques. Aim of this study was to apply a simple and inexpensive commercially available potentiometric method for the quantification of UIC based on iodine-specific ion-selective electrodes (ISE) in patients with thyroid diseases.

Methods: This retrospective study included patients with differentiated thyroid cancer $(n=286)$ and patients with hyperthyroidism of different etiologies $(n=203)$. Within the whole sample $(n=489) 20$ patients had previously (1 week-6 months) been exposed to iodine overload, either from contrast media $(n=8)$ or amiodarone $(n=12)$.

Results: In patients not exposed to iodine, the histogram showed that the distribution of UIC violated normality. The peak of the curve occurred between $5.0 \mu \mathrm{mol} / \mathrm{L}$ and $6.0 \mu \mathrm{mol} / \mathrm{L}$. Variability was sizeable (percent coefficient

*Corresponding author: Giampiero Giovacchini, Institute of Radiology and Nuclear Medicine, Stadtspital Triemli, Birmensdorferstr. 497, 8063 Zurich, Switzerland, Phone: +41 044466 1597, Fax: +41044 466 2959,

E-mail: giovacchinig@yahoo.com

Luca Giovanella: Oncology Institute of Southern Switzerland, Division of Nuclear Medicine and Thyroid Centre, Bellinzona, Switzerland

Andreas Haldemann: Institute of Radiology and Nuclear Medicine, Stadtspital Triemli, Zurich, Switzerland

Uwe Staub and Frank G. Füchsel: Department of Radiology and Nuclear Medicine, Stadtspital Waid, Zurich, Switzerland Peter Koch: Institute of Radiology and Nuclear Medicine, Stadtspital Triemli, Zurich, Switzerland; and Department of Radiology and Nuclear Medicine, Stadtspital Waid, Zurich, Switzerland of variation, \%CV: $66 \%$, 95\% confidence interval: $1.48-$ $18.72 \mu \mathrm{mol} / \mathrm{L})$. The group of exposed patients could be easily distinguished from not exposed patients (median UIC: $47.5 \mu \mathrm{mol} / \mathrm{L}$ vs. $5.42 \mu \mathrm{mol} / \mathrm{L}$ ). UIC was significantly correlated to urinary creatinine concentration, but normalization to urinary creatinine increased the inter-subject variability of UIC ( $\% \mathrm{CV}=96 \%$ vs. 66\%). In test-retest studies $(n=25)$ the intra-class correlation coefficient was 0.73 for UIC, 0.82 for creatinine and 0.64 for the UIC: creatinine ratio.

Conclusions: Iodine-specific ISE-based potentiometric methods can be successfully applied as an alternative to existing methods in patients with thyroid diseases. The promising characteristics of the method need to be confirmed in future larger prospective studies.

Keywords: exposure to non-radioactive iodine; hyperthyroidism; ion-selective potentiometry; radioiodine therapy; urinary iodine concentration.

\section{Introduction}

There is increasing interest in the measurement of urinary iodine concentration (UIC). Iodine is the major component of thyroid hormones and neurodevelopment of the fetus and breast-fed infants are crucially affected by maternal iodine intake $[1,2]$. The key indicator of population iodine nutrition recommended by the World Health Organization (WHO) is represented by the median concentration of UIC measured by a 24-h collection (gold standard) or by more practical single spot samples [2-5]: a median UIC of at least $100 \mu \mathrm{g} / \mathrm{L}$ represents an adequate iodine nutrition in a population and UIC equal to $300 \mu \mathrm{g} / \mathrm{L}$ was set as upper normal limit [3]. In population-based studies of UIC, the reliable and feasible collection of the 24-h urine samples is usually not possible. Therefore, less cumbersome spot urine samples are used [2-4]. There is generally good 
correlation between the single spot sample and the 24-h urine sample [6-8].

Knowledge of UIC is very important also in other medical scenarios, e.g., when diagnostic or therapeutic amounts of radioactivity need to be applied to patients with benign or malignant thyroid disease. In these patients iodine contamination, through iodine contrast media, iodine-containing medications (i.e., amiodarone), or chronic exposure to dietary iodine must be excluded [9-11].

Various methods based on different principles have been proposed to determine UIC. The vast majority of these methods measure the concentration of molecular iodine $\left(\mathrm{I}_{2}\right)$. Such methods include electrochemical detection, spectrophotometry, chemiluminescence, polarography, mass chromatography, gas chromatography, liquid chromatography and ion chromatography [12-19]. All these methods have some suboptimal properties $[15,16]$. For example, analytical methods, particularly inductivity coupled plasma mass spectroscopy, which is often considered the gold standard [14], is time consuming and requires expensive and complex instrumentation [17]. High-performance liquid chromatography methods based on ion chromatography or ion-paired reversed phase separation and detection by amperometry are alternative procedures, but they need special equipment too $[18,19]$. Photometric methods, most of which make use of the Sandell-Kolthoff reaction, require a pretreatment of the urine sample with acid digestion to remove several organic substances that influence the iodine catalytic effect $[15,16]$.

In the last years, iodide ( $\left.\mathrm{I}^{-}\right)$-specific ion-selective electrodes (ISE) based on different types of ionophores, have been developed that are applicable to determination of UIC with high selectivity and biocompatibility [20-22]. Ion potentiometric sensor techniques exhibit high selectivity, low detection limit, are inexpensive and rapid and therefore suitable for application in those medical clinical settings where rapid decision making is needed based on knowledge of UIC [16, 20-24]. Over the last years several potentiometric devices have been built and validated by different manufacturers so that ready for use potentiometric devices are commercially available. Moreover, the applied standard addition method excludes potential matrix effects introduced by urine components [25].

Aim of this retrospective study was to use a commercially available potentiometric device based on ISE to compare group differences in UIC among patients with benign and malignant thyroid diseases with and without previous exposure to non-radioactive iodine.

\section{Materials and methods}

\section{Population}

All patients with available UIC referred to the thyroid outpatient clinic of the Institute of Radiology and Nuclear Medicine of the Triemli Hospital, Zurich, Switzerland, between February 2013 and March 2014 were retrospectively included in this study. Mean age \pm standard deviation (SD) was $49 \pm 18$ years without significant ( $p>0.05$ ) differences between patients exposed to iodine and patients not exposed. The ratio between females and males in the population was 3:1. The ultimate sample of this retrospective study included 489 patients and included patients with the following diagnosis: 1) differentiated thyroid cancer, $n=286$ (papillary, $n=243$, follicular, $n=43$ ); 2) hyperthyroidism, $n=203$ (Grave's disease, $n=96$; unifocal adenoma or multinodular toxic goiter, $n=61$; subacute thyroiditis de Quervain with hyperthyroid onset, $n=26$; iodine-induced hyperthyroidism, $n=20$, including $n=8$ contrast media-induced hyperthyroidism and $\mathrm{n}=12$ amiodarone-induced hyperthyroidism).

Several physicians working in the thyroid outpatient clinic set the indication for the measurement of the UIC. In both groups UIC was measured at the first clinical evaluation and/or before radioiodine ablation or radioiodine therapy. In a limited number of patients $(n=25)$ two consecutive measurements of UIC within 1 week were performed to assess the reproducibility of the technique. Owing to the retrospective design of the study, not all variables of interest were available in all subjects.

This single-institution study was approved by the Cantonal Ethical Committee of Zurich, Switzerland and, owing to the retrospective design the study was waived from an informed consent.

\section{Potentiometric measurement of UIC}

Equipment: The potentiometric analysis was carried out with an iodide-selective electrode of Metrohm AG, 9101 Herisau, Switzerland, in combination with liquid junction, $\mathrm{Ag} / \mathrm{AgCl}$ reference electrode using a $781 \mathrm{pH} /$ ion meter produced by Metrohm (www.metrohm.ch).

Method: In contrast to the direct-potentiometric method, the known- or standard-addition-method was performed, whereby standards are added directly to the sample that needs to be analyzed [25]. This method is used in situations where sample matrix also contributes to the analytical signal (matrix effect) [25]. The volume and concentration of the added standards were stored as parameters in the ion meter.

Procedure: In total $8.0 \mathrm{~mL}$ of urine and $4.0 \mathrm{~mL} 5.0 \mathrm{M} \mathrm{NaNO}_{3}$ buffer are added into a vial. The procedure starts with the measurement of the voltage of the urine sample. Subsequently, according to the request on the display, $25 \mu \mathrm{L}, 100 \mu \mathrm{L}, 250 \mu \mathrm{L}$ and $500 \mu \mathrm{L}$ of the $1.0 \mathrm{mmol} / \mathrm{L}$ sodium iodide addition solutions are sequentially added. For each addition of sodium iodide the corresponding voltage is measured by the potentiometric device. These values are plotted on a Cartesian coordinate system, where the X-axis represents the iodine concentration and the Y-axis represents the voltage. Linear regression passing through the origin is used to fit these additions. The voltage of the urine is horizontally extrapolated to the regression line 
and the intercept is identified. The UIC is then calculated by vertical extrapolation of this intercept to the X-axis [25, 26]. After computation, the UIC $(\mu \mathrm{mol} / \mathrm{L})$ is automatically printed out by the potentiometric device. The whole procedure requires about $30 \mathrm{~min}$, including quality control.

Quality control: Before every run a measurement with $8.0 \mathrm{~mL}$ $5.0 \mu \mathrm{mol} / \mathrm{L}$ sodium iodide certified solution (www.metrohm.ch) was performed. Every 3 months external quality control with a commercially available quality control lyophilized urine ("ClinChek Level I and II" from www.recipe.de) was also performed.

Performance: The limit of detection (average value plus 3 standard deviations of 10 zero samples) was $0.05 \mu \mathrm{mol} / \mathrm{L}$. Spiking tests with $100 \mu \mathrm{L} 1.0 \mathrm{mmol} / \mathrm{L}$ sodium iodide to known urine samples showed a recovery of $97 \%-100 \%$.

\section{Statistical analysis}

Normality of the distribution of continuous variables was assessed graphically through histograms and formally with the KolmogorovSmirnov test. Comparisons of continuous normally distributed variables between two groups were performed using the t-test. Comparisons of not normally distributed continuous variables between two groups were performed using the Mann-Whitney U-test. Differences between categorical variables were assessed with the $\chi^{2}$ test. Comparison of UIC among the various clinical groups was performed with one-way analysis of variance (ANOVA) using Fisher's least significant difference as post-hoc test. Correlation between UIC and continuous variables of interests was performed with simple linear regression. A multiple linear regression model was used to assess gender differences in UIC after correcting for thyroid volume. Testretest reliability was assessed with the intra-class correlation coefficient using a two-way random model. Statistical significance was defined as $\mathrm{p}<0.05$. Statistical analysis was performed using the SPSS v 18 statistical software package (SPSS Inc, Chicago, IL, USA).

\section{Results}

Figure 1 shows the distribution of UIC in the sample $(n=469)$ after exclusion of patients with anamnestic evidence of iodine contamination $(n=20)$. The distribution of UIC does not present a typical bell-shaped form, owing to an asymmetric distribution over the selected intervals (skewness=1.60, kurtosis=3.24). The Kolmogorov-Smirnov test indicated that values of UIC are not normally distributed $(p<0.001)$. The peak of the curve occurs between $5 \mu \mathrm{mol} / \mathrm{L}$ and $6 \mu \mathrm{mol} / \mathrm{L}$, which correspond to about $630 \mu \mathrm{g} / \mathrm{L}$ and $760 \mu \mathrm{g} / \mathrm{L}$, respectively. The curve appears to level off starting by about $20 \mu \mathrm{mol} / \mathrm{L}$, even though UIC of few patients $(7 / 469,1.5 \%)$ clinically judged as not exposed to iodine contamination were observed above this threshold (see Discussion).

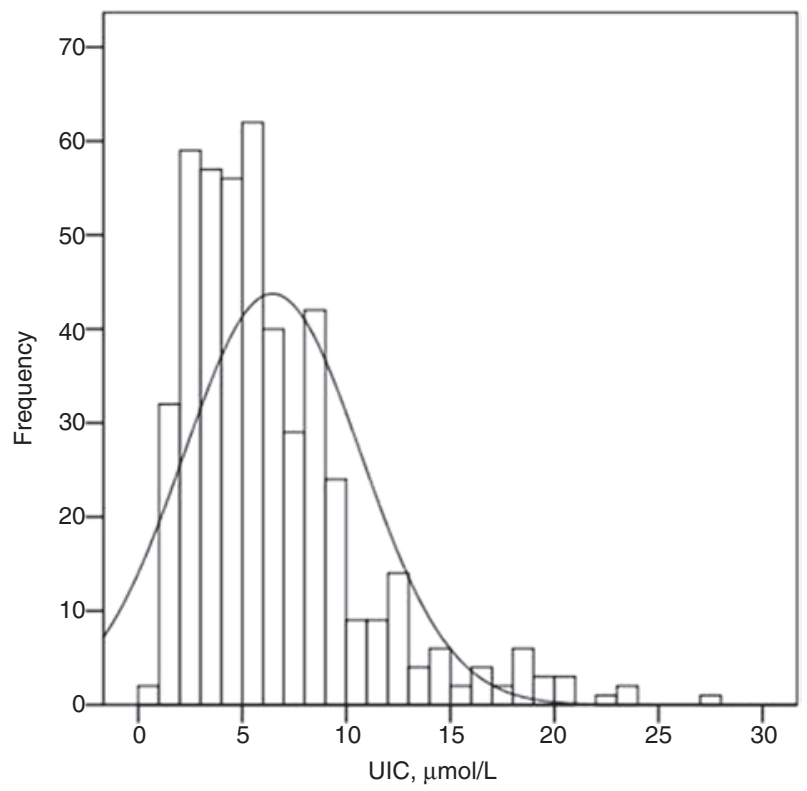

Figure 1: Histogram of UIC in patients with thyroid disease not exposed to non-radioactive iodine.

Descriptive statistics in not exposed patients and in exposed patients are reported in Tables 1 and 2. Figure 2 shows values of UIC among the different clinical groups of patients. As expected, the difference in mean UIC between patients with iodine-induced hyperthyroidism and the remaining diagnostic categories is remarkable $(\mathrm{p}<0.001)$. Mean \pm SD in patients with iodine-induced hyperthyroidism was $69.3 \pm 54.5 \mu \mathrm{mol} / \mathrm{L}$ and median was $47.5 \mu \mathrm{mol} / \mathrm{L}$. One patient exposed to hydrophilic contrast media 1 month before the test had UIC in the physiological range (9.52 $\mu \mathrm{mol} / \mathrm{L})$ (see Discussion). For each group the graph displays outliers, defined as patients with UIC $>75 \%$ percentile plus $1.15 *$ the interquartile range, or extreme cases, defined as patients with UIC $>75 \%$ percentile plus $3 *$ the interquartile range. Global effect in the one-way ANOVA among the remaining groups did not reach statistical significance $(\mathrm{F}=0.97, \mathrm{p}=0.40)$. Consequently, UIC was very similar (Graves' disease $=6.24 \pm 4.55 \mu \mathrm{mol} / \mathrm{L}$, thyroid cancer $=6.60 \pm 4.28 \mu \mathrm{mol} / \mathrm{L}$, uninodular or multinodular toxic goiter $=6.02 \pm 3.70 \mu \mathrm{mol} / \mathrm{L}$, subacute thyroiditis de Quervain with hyperthyroid onset $=6.52 \pm 4.44 \mu \mathrm{mol} / \mathrm{L}$ ). Note (Table 2) in not exposed subjects the high inter-subject variability in the measurement of UIC, as expressed by the percent coefficient of variation $(\% \mathrm{CV}, 66 \%)$ or by the $95 \%$ confidence interval ( $95 \%$ CI 1.48-18.72 $\mu \mathrm{mol} / \mathrm{L}$ ). There was no significant difference in urinary creatinine concentration between exposed and not exposed patients $(\mathrm{p}=0.22)$.

In test-retest studies in not exposed subjects baseline UIC was $6.33 \pm 3.34 \mu \mathrm{mol} / \mathrm{L}$, while retest UIC equaled 
Table 1: Descriptive statistics of the urine concentration of different biochemical variables in patients not exposed to non-radioactive iodine $(n=469)$.

\begin{tabular}{|c|c|c|c|c|}
\hline & lodide, $\mu \mathrm{mol} / \mathrm{L}$ & lodide, $\mu \mathrm{g} / \mathrm{L}$ & Creatinine, $\mathrm{g} / \mathrm{L}$ & lodide: creatinine, $\mu \mathrm{g} / \mathrm{g}$ \\
\hline Median & 5.42 & 688 & 0.71 & 97.0 \\
\hline Mean $\pm S D$ & $6.45 \pm 4.27$ & $818 \pm 542$ & $0.92 \pm 0.76$ & $134.2 \pm 128.7$ \\
\hline$(\min -\max )$ & $(0.72-27.55)$ & $(91-3496)$ & $(0.06-6.91)$ & (12-1398) \\
\hline$\% \mathrm{CV}$ & $66 \%$ & $66 \%$ & $83 \%$ & $96 \%$ \\
\hline $95 \% \mathrm{Cl}$ & $1.48-18.72$ & $189-2376$ & $0.13-2.65$ & $21.7-437.2$ \\
\hline Interquartile range & 4.97 & 650 & 0.94 & 99 \\
\hline
\end{tabular}

Table 2: Descriptive statistics of the urine concentration of different biochemical variables in patients exposed to non-radioactive iodine $(n=20)$.

\begin{tabular}{|c|c|c|c|c|}
\hline & lodide, $\mu \mathrm{mol} / \mathrm{L}$ & lodide, $\mu \mathrm{g} / \mathrm{L}$ & Creatinine, $\mathrm{g} / \mathrm{L}$ & lodide: creatinine, $\mu \mathrm{g} / \mathrm{L}$ \\
\hline Median & 47.5 & 6034 & 0.94 & 731 \\
\hline Mean \pm SD & $69.3 \pm 54.5$ & $8793 \pm 6923$ & $1.06 \pm 0.47$ & $1053 \pm 1010$ \\
\hline$(\min -\max )$ & $(9.52-199.2)$ & $(1208-25278)$ & $(0.36-2.07)$ & $(69-3685)$ \\
\hline$\% \mathrm{CV}$ & $79 \%$ & $79 \%$ & $44 \%$ & $96 \%$ \\
\hline $95 \% \mathrm{Cl}$ & $9.52-198.2$ & $1208-25156$ & $0.36-2.07$ & $69-3678$ \\
\hline Interquartile range & 51.0 & 6478 & 0.63 & 787 \\
\hline
\end{tabular}

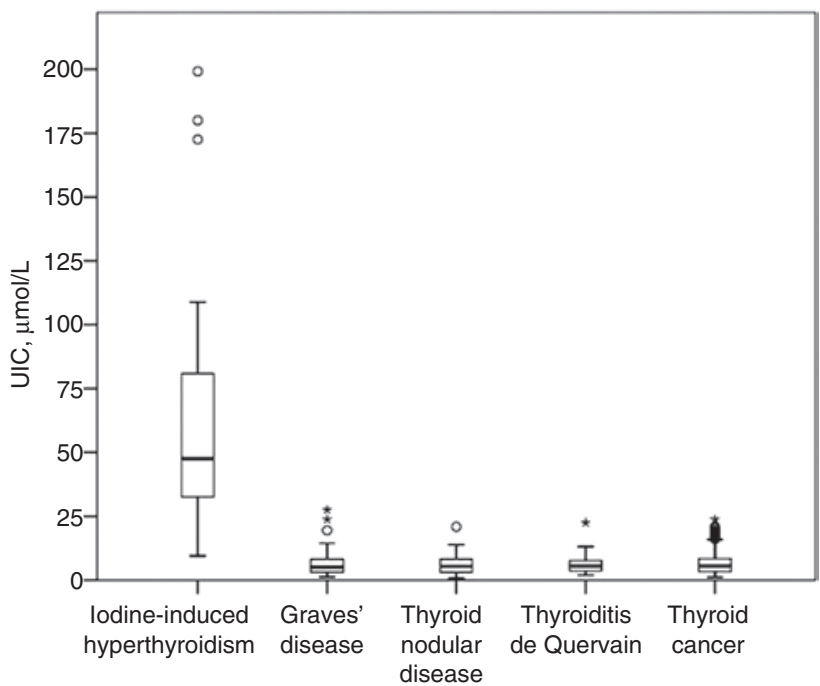

Figure 2: Box-and-whisker plot of the UIC ( $\mu \mathrm{mol} / \mathrm{L})$ in the different diagnostic groups.

The ends of the whiskers represent minimum and maximum values. O represents outliers, * represents extreme cases (see text fur further details).

5.90 $\pm 2.18 \mu \mathrm{mol} / \mathrm{L}$ (paired t-test, $\mathrm{p}=0.43$ ). In this small group $(n=25)$ the ratio between the test and the retest value of the UIC had a median of 1.05 (range 0.47-3.29). The intra-class correlation coefficient was 0.73 for UIC, 0.82 for creatinine and 0.64 for the UIC:creatinine ratio (Figure 3).

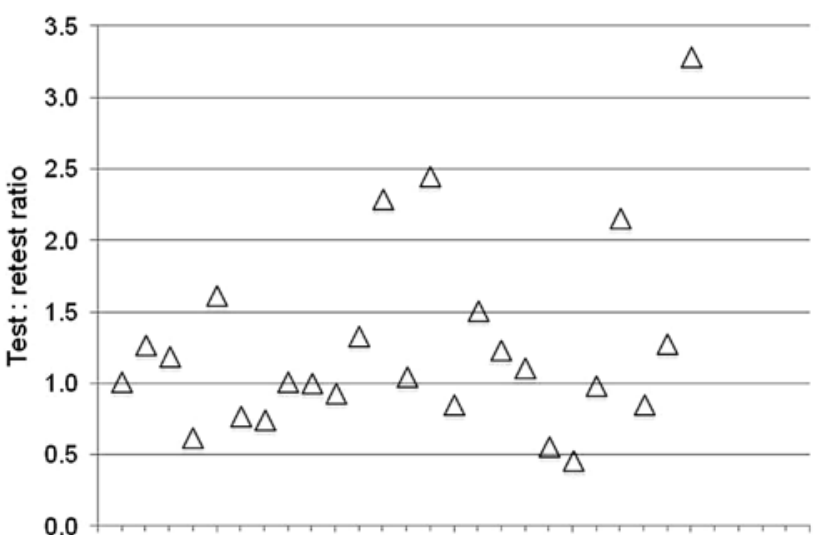

Figure 3: Ratio between test and retest values of UIC in not exposed patients $(n=25)$.

A positive relationship was found between UIC and creatinine in not exposed patients $(n=469, r=0.42$, $\mathrm{F}=99.8, \mathrm{p}<0.001$ ) (Figure 4). The equation of the linear regression was: $\mathrm{Y}=2.35 \mathrm{X}+4.28$. UIC was normalized on a subject-by-subject basis to urinary creatinine concentration. However, normalization of UIC to creatinine concentration increased the inter-subject variability of UIC (\% $\mathrm{CV}=96 \%$ vs. $66 \%$ ) (Table 1 ).

Thyroid volume was significantly smaller in women than in men $(n=34,24.6 \pm 14.4 \mathrm{~mL}$ vs. $38.1 \pm 16.8 \mathrm{~mL})$ $(p=0.031)$. UIC was significantly lower in women 


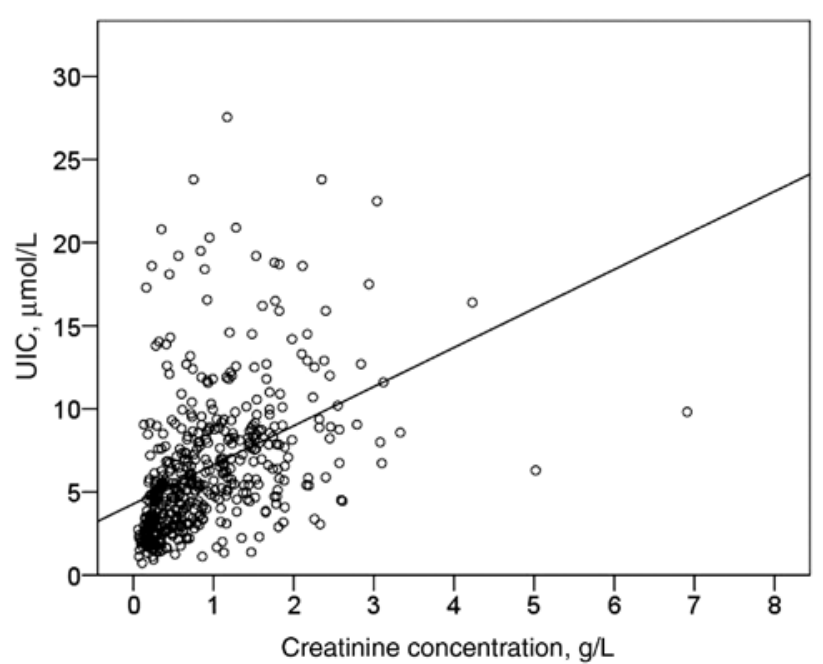

Figure 4: Linear regression between UIC and creatinine urinary concentration in not exposed patients $(n=469)$.

The regression equation was: $\mathrm{Y}=2.35 \mathrm{X}+4.28(\mathrm{r}=0.42, \mathrm{~F}=3.4$, $\mathrm{p}<0.001)$.

$(6.44 \pm 3.84 \mu \mathrm{mol} / \mathrm{L})$ than in men $(8.42 \pm 4.10 \mu \mathrm{mol} / \mathrm{L})$ $(p=0.026)$. After correcting for thyroid volume, the gender difference in UIC lost statistical significance $(\mathrm{F}=0.60$, $\mathrm{p}=0.44)$.

UIC was also plotted against other variables of interest. No significant relationship was found between UIC and age $(\mathrm{n}=123, \mathrm{~F}=0.11, \mathrm{p}=0.74)$, between UIC and body weight $(\mathrm{n}=101, \mathrm{~F}=1.16, \mathrm{p}=0.28)$ or between UIC and urine $\mathrm{pH}(\mathrm{n}=14, \mathrm{~F}=0.081, \mathrm{p}=0.78)$. Neither plasma concentration of total or free triiodothyronine nor plasma concentration of thyroxine correlated with UIC either in the whole group or in each of the different subgroups (data not shown).

One typical example illustrating the importance of knowledge of UIC for the differential diagnosis of hyperthyroidism is shown in Figure 5.

\section{Discussion}

In this study we have used a commercially available potentiometric method to investigate the distribution of UIC in patients with thyroid disease not exposed to non-radioactive iodine and to assess group differences in UIC among different groups of patients with thyroid diseases exposed and not exposed to non-radioactive iodine. Results indicated that the technique allows stratification of UIC according to the clinical diagnosis, as desirable. This method has the noteworthy advantage of being inexpensive and more rapid in comparison to many others [12-14]. Therefore, other than being manual, the potentiometric method is gifted with all favorable characteristics that are

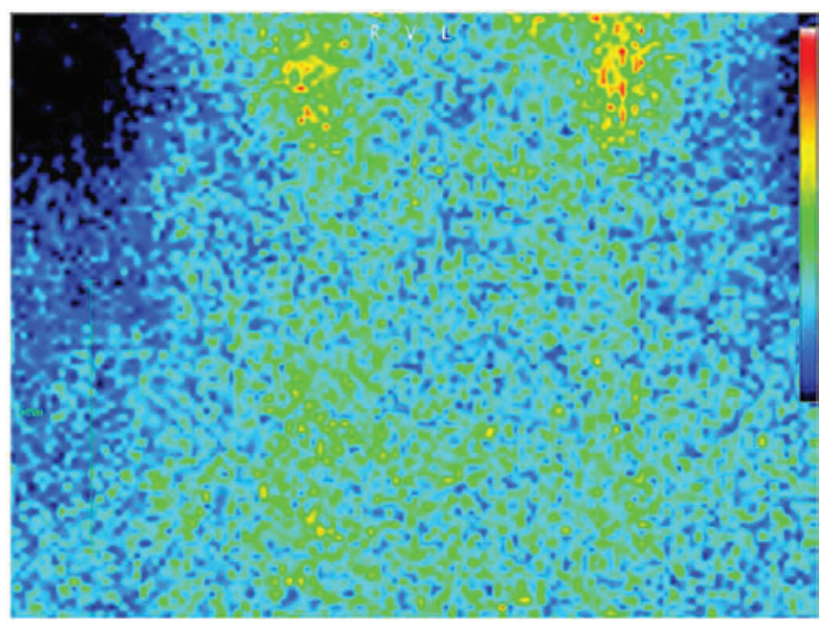

Figure 5: Example illustrating the importance of knowledge of UIC for the differential diagnosis of hyperthyroidism.

Patient \#1 is a 75-year-old man who developed subclinical hyperthyroidism after 7 years of medical therapy with amiodarone. The patient was asymptomatic. Laboratory results showed: $\mathrm{TSH} \leq 0.01$ $\mathrm{mU} / \mathrm{L}(0.3-4.2)$, free triiodothyronine ( $\mathrm{fT} 3)=7.7 \mathrm{pmol} / \mathrm{L}(3.1-6.8)$ and free thyroxine (fT4) was $27.2 \mathrm{pmol} / \mathrm{L}(12.0-22.0)$, antibodies against thyroperoxidase (TPO-Ab): $14 \mathrm{U} / \mathrm{mL}(0-34)$, antibodies against TSH (TRAb): $<0.3 \mathrm{IU} / \mathrm{L}(<1.8)$. Neck echography showed a thyroid with

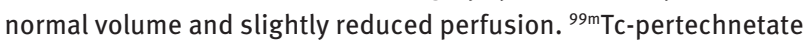
scintigraphy showed no significant tracer uptake in the thyroid region and visualization of salivary glands. Thyroid uptake was $0.2 \%(0.5 \%-2.0 \%)$. UIC was $56.2 \mu \mathrm{mol} / \mathrm{L}$. A subacute thyroiditis de Quervain with hyperthyroid onset was excluded and the ultimate diagnosis was type 2 amiodarone-induced thyrotoxicosis.

necessary to rule out iodine contamination in the nuclear medicine setting. The advantageous profiles of potentiometric methods have been previously highlighted and a rapid development of the technique has been advocated [20, 24, 26-28]. Nowadays, several potentiometric devices have been developed and are commercially available. In Switzerland, validation of commercially available potentiometric devices is ensured by the manufacturer before the release on the market. Moreover, only verification tests and routine quality controls are needed for their clinical use (www.seco.admin.ch/sas).

Knowledge of UIC is very important for the management of patients affected by benign or malignant thyroid diseases. Guidelines regarding the management of the differentiated thyroid cancer recommend a low iodine diet for about 2 weeks prior to radioiodablation, postponement of radioiodine ablation when the UIC is above $150-300 \mu \mathrm{g} / \mathrm{L}$, or for at least 3 months after intravenous infusion of iodinated contrast agents or after withdrawal of amiodarone [9-11]. However, recent studies showed that 1 month could be sufficient to allow recovery after exposure to hydrophilic iodinated contrast agents for neck or chest 
computed tomography [29, 30]. Conversely, after exposure to lipophilic hepatobiliary agents or to amiodarone, UIC may remain increased for several months [31,32].

Our results replicated previous findings indicating a large variability in UIC $[2-5,33-35]$. To reduce the variability of the single spot UIC, normalization to urine creatinine (expressed in $\mu \mathrm{g}$ iodine/g creatinine) has been often adopted. Unfortunately, creatinine values are dependent on sex, age and muscular mass [33, 34], which mandates the collection of a huge database before reliable clinical application and requires a more cumbersome definition of normal values according to these variables [4,7]. The effect of creatinine on the variability of the measurement of UIC is also disputed. For example, Kim et al. found that the 24-h urinary iodine excretion correlated more strongly with the iodine:creatinine ratio rather than with the simple UIC [36]. Other authors discourage the use of the iodine:creatinine ratio because of its higher variability $[2,35]$. Our results are consistent with the latter observation and fail to give evidence of a substantial advantage in normalization to urine creatinine levels. Measurements of creatinine are more reliable than measurements of UIC in the single subject, but the lack of a strong relationship between the physiology of iodine and the physiology of creatinine makes the ratio UIC:creatinine in this sample less useful.

In the literature several units have been used to refer to UIC, even though most international societies, including the WHO, adopted $\mu \mathrm{g} / \mathrm{L}$. Our potentiometric methodology expresses UIC directly in $\mu \mathrm{mol} / \mathrm{L}$ according to the guidelines of the International System of Units, but results can easily be transformed in $\mu \mathrm{g} / \mathrm{L}$ after multiplication for the molecular weight of iodine (126.9 Dalton). Observation of Table 1 reveals that median UIC in not exposed patients $(688 \mu \mathrm{g} / \mathrm{L})$ is about $2-3$ times higher than the upper range of the normal values obtained with the Sandell-Kolthoff reaction $(300 \mu \mathrm{g} / \mathrm{L})[3,37]$ and that the higher limit of the $95 \%$ confidence interval $(2376 \mu \mathrm{g} / \mathrm{L})$ is about eight times higher. This apparent bias is most likely due to the fact that acid environment of urine favors the formation of the anionic form $\mathrm{I}^{-}$against the neutral molecular form $\mathrm{I}_{2}$. This explains why the vast majority (up to $>90 \%$ ) of total iodine in the urine is present as iodide $\left(\mathrm{I}^{-}\right)$[12]. Since ISE-based potentiometry measures exclusively $\mathrm{I}^{-}$, while the SandellKolthoff reaction measures only $\mathrm{I}_{2}$, systematically higher UIC in this study was expected. Another possible explanation is that the acid reactant used in the Sandell-Kolthoff reaction might reduce the catalytic activity of $\mathrm{I}_{2}[15,16]$ and thereby possibly underestimate the real concentration of $\mathrm{I}_{2}$ in the urine. According to the first hypothesis, to compare the potentiometric $\mathrm{I}^{-}$-based UIC expressed in $\mu \mathrm{g} / \mathrm{L}$ to the results of the $\mathrm{I}_{2}$-based Sandell-Kolthoff reaction, a division of the UIC potentiometric value (expressed in $\mu \mathrm{g} / \mathrm{L}$ after multiplication for the molecular weight of iodine) for the presumed $\mathrm{I}^{-} / \mathrm{I}_{2}$ ratio in the urine of 9 [12] is necessary. Alternatively, the corrected potentiometric $\mathrm{I}^{-}$-based UIC in $\mu \mathrm{g} / \mathrm{L}$ can be obtained by multiplying the original UIC expressed in $\mu \mathrm{mol} / \mathrm{L}$ for the single correction factor of 14.1.

The distribution of UIC in this sample showed that the $2.5 \% \mathrm{CI}$ and the $97.5 \% \mathrm{CI}$ equaled $1.48 \mu \mathrm{mol} / \mathrm{L}$ and $18.72 \mu \mathrm{mol} / \mathrm{L}$, respectively. Based on the descriptive analysis and visual inspection of the histogram, an upper value of $20 \mu \mathrm{mol} / \mathrm{L}$ could be adopted to exclude iodine contamination when applying radioactivity. This is a reasonable practical rounding of the $97.5 \%$ confidence interval that could be used to minimize false positives. Even though calculation based on literature values [12] need to be interpreted with caution especially when dealing with a relatively small sample, it is interesting to note that $20 \mu \mathrm{mol} / \mathrm{L}$, calculated with the I--based potentiometric method, corresponds after transformation to $280 \mu \mathrm{g} / \mathrm{L}$ of the $\mathrm{I}_{2}$-based Sandell-Kolthoff reaction and compares favorably with the limit of $300 \mu \mathrm{g} / \mathrm{L}$ set by the WHO to define normal UIC [3]. Recommendation of a cut-off between 150 and $300 \mu \mathrm{g} / \mathrm{L}$ [9-11] suggests that UIC cut-off might be adapted to the clinical setting. However, because of the very limited number of patients studied with scintigraphy and uptake measurements, we currently do not have any element to support clinically adapted thresholds and suggest that the same threshold of $20 \mu \mathrm{mol} / \mathrm{L}$ be used for both diagnostic imaging and therapy.

Our study also indicates that while the vast majority of normal subjects can be easily differentiated by patients recently exposed to iodine, there is a gray zone around 20-30 $\mu \mathrm{mol} / \mathrm{L}$, where some overlap takes place and the differential diagnosis may be difficult if the anamnesis is not conclusive. Indeed a factor $2-3$ variability in the UIC is encountered occasionally also in subjects not exposed to iodine, despite the overall reliability of the technique is good (intra-class correlation coefficient $=0.73$; median test-retest ratio $=1.05$ ). The sources of variability in UIC are multiple and include circadian rhythms, sensitivity to hydration, and exposure to dietary or environmental iodine $[38,39]$. As a consequence, in selected patients who have borderline UIC and are candidates to therapy, it might be preferable to repeat UIC after one or few days before proceeding to the application of radioactivity.

The main limit of the study, which is due to the retrospective design, is that we could not systemically assess the UIC threshold at which a sizable inhibition of thyroid uptake occurs. Thyroid uptake of ${ }^{131} I$ and ${ }^{99 m}$ Tc-pertechnetate were inversely proportional to UIC $[40,41]$. The dynamics of the iodine overload on thyroid 
function and scintigraphic patterns are indeed complex, and depend on several factors including time from exposure, amount of iodine, pattern (acute vs. chronic) of exposure and chemical form of the iodinated compound $[31,32,40,42,43]$.

A second limit of the study, which is also inherent to the retrospective design, is that our results could not be directly compared to those obtained with the SandellKolthoff reaction.

In summary, we have applied a commercially available iodine-selective ISE-based potentiometric method for measurement of UIC in patients with thyroid disease. This preliminary clinical application suggests that using the ISE-based potentiometric technique allows reliable measurement of UIC and clinical decision-making. This method is inexpensive, rapid and it can be successfully applied as an alternative to existing methods for excluding iodine contamination before administration of diagnostic or therapeutic amounts of radiopharmaceuticals. The technique provides values of UIC that compare favorably with those obtained by well established, yet more expensive and cumbersome, techniques.

Author contributions: All the authors have accepted responsibility for the entire content of this submitted manuscript and approved submission.

Financial support: None declared.

Employment or leadership: None declared.

Honorarium: None declared.

Competing interests: The funding organization(s) played no role in the study design; in the collection, analysis, and interpretation of data; in the writing of the report; or in the decision to submit the report for publication.

\section{References}

1. Delange F, Wolff $P$, Gnat D, Dramaix M, Pilchen $M$, Vertongen $F$. lodine deficiency during infancy and early childhood in Belgium: does it pose a risk to brain development? Eur J Pediatr 2001;160:251-4.

2. Amouzegar A, Khazan M, Hedayati M, Azizi F. An assessment of the iodine status and the correlation between iodine nutrition and thyroid function during pregnancy in an iodine sufficient area. Eur J Clin Nutr 2014;68:397-400.

3. WHO/UNICEF/ICCIDD: International Council for the Control of lodine Deficiency Disorders. Assessment of iodine deficiency disorders and monitoring their elimination, 3rd ed. Geneva: World Health Organization, 2007.

4. Vejbjerg P, Knudsen N, Perrild H, Laurberg P, Andersen S, Rasmussen LB, et al. Estimation of iodine intake from various urinary iodine measurements in population studies. Thyroid 2009;19:1281-6.
5. Konig F, Andersson M, Hotz K, Aeberli I, Zimmermann MB. Ten repeat collections for urinary iodine from spot samples or 24-h samples are needed to reliably estimate individual iodine status in women. J Nutr 2011;141:2049-54.

6. Vanacor R, Soares R, Manica D, Furlanetto TW. Urinary iodine in $24 \mathrm{~h}$ is associated with natriuresis and is better reflected by an afternoon sample. Ann Nutr Metab 2008;53:43-9.

7. Perrine CG, Cogswell ME, Swanson CA, Sullivan KM, Chen TC, Carriquiry AL, et al. Comparison of population iodine estimates from 24-h urine and timed-spot urine samples. Thyroid 2014;24:748-57.

8. Thomson CD, Smith TE, Butler KA, Packer MA. An evaluation of urinary measures of iodine and selenium status. J Trace Elem Med Biol 1996;10:214-22.

9. Pacini F, Schlumberger M, Dralle H, Elisei R, Smit JW, Wiersinga W, et al. European consensus for the management of patients with differentiated thyroid carcinoma of the follicular epithelium. Eur J Endocrinol 2006;154:787-803.

10. Luster M, Clarke SE, Dietlein M, Lassmann M, Lind P, Oyen WJ, et al. Guidelines for radioiodine therapy of differentiated thyroid cancer. Eur J Nucl Med Mol Imaging 2008;35:1941-59.

11. Stokkel MP, Handkiewicz Junak D, Lassmann M, Dietlein M, Luster M. EANM procedure guidelines for therapy of benign thyroid disease. Eur J Nucl Med Mol Imaging 2010;37:2218-28.

12. Minakata K, Yamagishi I, Kanno S, Nozawa H, Suzuki M, Suzuki O. Determination of iodide in urine using electrospray ionization tandem mass spectrometry. J Chromatogr B Analyt Technol Biomed Life Sci 2010;878:1683-6.

13. Zimmermann MB. Methods to assess iron and iodine status. Br J Nutr 2008;99(Suppl 3):S2-9.

14. Jooste PL, Strydom E. Methods for determination of iodine in urine and salt. Best Pract Res Clin Endocrinol Metab 2010;24:77-88.

15. Mina A, Favaloro EJ, Koutts J. A robust method for testing urinary iodine using a microtitre robotic system. J Trace Elem Med Biol 2011;25:213-7.

16. Grimm G, Lindorfer $H$, Kieweg $H$, Marculescu R, Hoffmann M, Gessl A, et al. A simple micro-photometric method for urinary iodine determination. Clin Chem Lab Med 2011;49:1749-51.

17. Macours P, Aubry JC, Hauquier B, Boeynaems JM, Goldman S, Moreno-Reyes R. Determination of urinary iodine by inductively coupled plasma mass spectrometry. J Trace Elem Med Biol 2008;22:162-5.

18. Rendl J, Seybold S, Borner W. Urinary iodide determined by paired-ion reversed-phase HPLC with electrochemical detection. Clin Chem 1994;40:908-13.

19. Yabu Y, Miyai K, Endo Y, Hata N, lijima Y, Hayashizaki S, et al. Urinary iodide excretion measured with an iodideselective ion electrode: studies on normal subjects of varying ages and patients with thyroid diseases. Endocrinol Jpn 1988;35:391-8.

20. Zhang W, Mnatsakanov A, Hower R, Cantor H, Wang Y. Urinary iodine assays and ionophore based potentiometric iodide sensors. Front Biosci 2005;10:88-93.

21. Xu WJ, Yuan R, Chai YQ, Zhang TT, Liang WB, Wu X. Fabrication of an iodide-selective electrode based on phthalocyaninatotitanium(IV) oxide and the selective determination of iodide in actual samples. Anal Bioanal Chem 2008;392:297-303. 
22. Svancara I, Ogorevc B, Novic M, Vytras K. Simple and rapid determination of iodide in table salt by stripping potentiometry at a carbon-paste electrode. Anal Bioanal Chem 2002;372: 795-800.

23. Kazi TG, Kandhro GA, Afridi HI, Kazi N, Baig JA, Arain MB, et al. Interaction of copper with iron, iodine, and thyroid hormone status in goitrous patients. Biol Trace Elem Res 2010;134: 265-79.

24. Odink J, Bogaards JJ, Sandman H, Egger RJ, Arkesteyn GA, de Jong P. Excretion of iodide in 24-h urine as determined by ion-pair reversed-phase liquid chromatography with electrochemical detection. J Chromatogr 1988;431:309-16.

25. Gottardi W. Die potentiometrische Bestimmung von lodid in Harn unter Berücksichtigung der Chlorid-Störung. Lab Med 1992;16:283-91.

26. Kandhro GA, Kazi TG, Sirajuddin, Kazi N, Afridi HI, Arain MB, et al. Evaluation of iodine concentration in serum and urine of hypothyroid males using an inexpensive and rapid method. Pak J Anal Environ Chem 2009;10:67-75.

27. Kazi TG, Wadhwa SK, Afridi HI, Kazi N, Kandhro GA, Baig JA, et al. Interaction of cadmium and zinc in biological samples of smokers and chewing tobacco female mouth cancer patients. J Hazard Mater 2010;176:985-91.

28. Sohn SY, Choi JY, Jang HW, Kim HJ, Jin SM, Kim SW, et al. Association between excessive urinary iodine excretion and failure of radioactive iodine thyroid ablation in patients with papillary thyroid cancer. Thyroid 2013;23:741-7.

29. Sohn SY, Choi JH, Kim NK, Joung JY, Cho YY, Park SM, et al. The impact of iodinated contrast agent administered during preoperative computed tomography scan on body iodine pool in patients with differentiated thyroid cancer preparing for radioactive iodine treatment. Thyroid 2014;24:872-7.

30. Padovani RP, Kasamatsu TS, Nakabashi CC, Camacho CP, Andreoni DM, Malouf EZ, et al. One month is sufficient for urinary iodine to return to its baseline value after the use of water-soluble iodinated contrast agents in post-thyroidectomy patients requiring radioiodine therapy. Thyroid 2012;22: 926-30.

31. Rao RH, McCready VR, Spathis GS. Iodine kinetic studies during amiodarone treatment. J Clin Endocrinol Metab 1986;62:563-8.
32. van der Molen AJ, Thomsen HS, Morcos SK, Contrast Media Safety Committee, European Society of Urogenital Radiology (ESUR). Effect of iodinated contrast media on thyroid function in adults. Eur Radiol 2004;14:902-7.

33. Knudsen N, Christiansen E, Brandt-Christensen M, Nygaard B, Perrild H. Age- and sex-adjusted iodine/creatinine ratio. A new standard in epidemiological surveys? Evaluation of three different estimates of iodine excretion based on casual urine samples and comparison to $24 \mathrm{~h}$ values. Eur J Clin Nutr 2000;54:361-3.

34. Andersen S, Karmisholt J, Pedersen KM, Laurberg P. Reliability of studies of iodine intake and recommendations for number of samples in groups and in individuals. Br J Nutr 2008;99:813-8.

35. Furnee CA, van der Haar F, West CE, Hautvast JG. A critical appraisal of goiter assessment and the ratio of urinary iodine to creatinine for evaluating iodine status. Am J Clin Nutr 1994;59:1415-7.

36. Kim HK, Lee SY, Lee JI, Jang HW, Kim SK, Chung HS, et al. Usefulness of iodine/creatinine ratio from spot-urine samples to evaluate the effectiveness of low-iodine diet preparation for radioiodine therapy. Clin Endocrinol (Oxf) 2010;73:114-8.

37. Soldin OP, Soldin SJ, Pezzullo JC. Urinary iodine percentile ranges in the United States. Clin Chim Acta 2003;328:185-90.

38. Als C, Helbling A, Peter K, Haldimann M, Zimmerli B, Gerber H. Urinary iodine concentration follows a circadian rhythm: a study with 3023 spot urine samples in adults and children. J Clin Endocrinol Metab 2000;85:1367-9.

39. Rasmussen LB, Ovesen L, Christiansen E. Day-to-day and within-day variation in urinary iodine excretion. Eur J Clin Nutr 1999;53:401-7.

40. Follis RH Jr., Vanprapa K, Damrongsakdi D. Studies on iodine nutrition in Thailand. J Nutr 1962;76:159-73.

41. Reinhardt MJ, Hogerle S, Trupkovic T, Krause TM, Moser E. Influence of urinary iodine excretion on thyroid technetium$99 \mathrm{~m}$ pertechnetate uptake with and without TSH suppression: what happens when iodine supply increases? Eur J Nucl Med 1998;25:1475-81.

42. Zimmermann MB, Ito Y, Hess SY, Fujieda K, Molinari L. High thyroid volume in children with excess dietary iodine intakes. Am J Clin Nutr 2005;81:840-4.

43. Wolff J. Perchlorate and the thyroid gland. Pharmacol Rev 1998;50:89-105. 